\title{
REVITALISASI SUTAN TAKDIR ALISJAHBANA DALAM PERJUANGAN DAN PERTUMBUHAN BAHASA INDONESIA: SUATU ANALISIS ISI
}

\author{
Kasno Atmo Sukarto \\ Fakultas Sastra, Universitas Nasional \\ Pos-el: kasnoas@yahoo.com
}

\begin{abstract}
ABSTRAK
Penelitian yang berjudul Revitalisasi Sutan Takdir Alisjahbana dalam Perjuangan dan Pertumbuhan ahasa Indonesia: Suatu Analisis Isi ini bertujuan untuk mendeskripsikan kembali pandangan Sutan Takdir Alisjahbana (STA) dalam Perjuangan dan Pertumbuhan bahasa Indonesia. Dasar teori penelitian ini adalah Konsep STA yaitu “... berani berpikir dan berusaha menuju penyempurnaan bahasa Indonesia. Metode yang digunakan dalam tulisan ini adalah deskriptif analisis, yaitu mendeskripsikan hal-hal yang berkaitan dengan ikhwal perjuangan dan pertumbuhan bahasa Indonesia. Analissis yang diancangkan adalah berkenaan dengan 1) bahasa Indonesia sebagai bahasa persatuan. 2) Pelajaran bahasa Indonesia 3) Pujangga Baru mementingkan kesusaateraan dan bahasa Indonesia. 4) Hakikat bahasa Indonesia. 5) Bahasa Indonesia dengan Sekolah Tinggi Kesusateraan. 6) Penerjemahan. 7) Pedoman penyusunan Tata Bahasa Baru Bahasa Indonesia. 8) Rancangan pelajaran bahasa Indonesia di perguruan tinggi. Hasilnya adalah bahasa Indonesia sebagai bahasa nasional dan bahasa negara selalu tumbuh dan berkembang secara dinamis.
\end{abstract}

Kata Kunci: bahasa persatuan, bahasa Indonesia, tata bahasa Indonesia, bahasa Indonesia di perguruan tinggi

\begin{abstract}
The study, entitled revitalization of the STA in the struggle and the growth of Indonesian aimed to describe the back view of the STA. The theoretical basis of this study is the concept of STA in the struggle and the growth of Indonesian. The method used in this paper is a descriptive analysis, namely, to describe things relating to matters of the struggle and the growth of Indonesian. The analysis in respect diancangkan 1. Indonesian language as the national language, 2. Indonesian language teaching ., 3. The new poet concerned with literature and Indonesian, 4. the nature of Indonesian, 5. Indonesian with a high school literature, 6. Translation, 7. The guidelines for the preparation of the new Indonesian grammar, 8. Draft Indonesian lessons in college. The result is Indonesian as national language and state language always growing and developing dinamically.
\end{abstract}

Key Word: National Languange, Indonesian language, Indonesian grammar, Indonesian lessons in college

\section{PENDAHULUAN \\ Latar Belakang}

Saat ini berbicara tentang sejarah dan pengembangan bahasa Indonesia tidak dapat dielakkan lagi. Hal itu terbukti adanya globalisasi yang tidak bisa dihindari lagi oleh khalayak yang selalu menggunakan bahasa Indonesia dalam berkomunikasi baik secara lisan maupun secara tertulis. Sehubungan dengan itu, untuk mengantisipasi globalisasi perlu adanya 
perencanaan bahasa yang matang dan terarah sesuai dengan garis-garis besar haluan kebahasaan. Hal itu sesuai dengan pandangan Kasno dan Anzali ( 2015: 39) yang menyatakan bahwa dalam era globalisasi ini, bahasa akan menyentuh semua aspek kehidupan masyarakat yang dipakai dan diyakini oleh masyarakat pemakai bahasa, misalnya bahasa Inggris merupakan bahasa internasional yang pemakainya lebih dari satu miliar. Namun, bukan hanya bahasa Inggris saja yang ingin mendunia, melainkan juga bahasa Indonesia yang mempunyai fungsi sebagai bahasa nasional dan bahasa negara Republik Indonesia juga mempunyai fungsi yaitu mencakup segala aspek kehidupan manyarakat Indonesia dan masyarakat dunia.

Jika kita mengacu pada Sumpah Pemuda tanggal 28 Oktober 1928 pada butir ketiga berbunyi “ Kami putera dan puteri Indonesia menjunjung bahasa persatuan, bahasa Indonesia". Artinya bahasa Indonesia mempunyai cakupan yang luas untuk mempersatukan bangsa Indonesia yang beragam suku, agama, dan bahasa. Untuk masalah bahasa, khususnya bahasa daerah di Indonesia terdapat 646 bahasa daerah (sumber data hasil penelitian Pengembangan dan Pelindungan, Badan Pengembangan dan Pembinaan Bahasa sampai dengan 18 Oktober 2016 yang meliputi Sumatera 21 bahasa, Kalimantan 53 bahasa, Sulawesi 53 bahasa, Maluku 65 bahasa, Jawa 5 bahasa, Bali dan Nusa Tenggara 73 bahasa, dan Papua 376 bahasa).

Jumlah bahasa daerah di Indonesia 646 itu tidak termasuk dialek. Jadi tanggung jawab kita terhadap bahasa Indonesia akan lebih berat karena tidak mungkin masyarakat kita akan berkomunikasi melalui bahasa daerah masing-masing untuk berkomunikasi antarwarga. Oleh karena itu, hanya dengan bahasa Indoneisa lah bangsa Indonesia berkomunikasi antarsesama baik komunikasi antarsuku maupun antarwilayah di Indonesia ini.

Konsep tersebut di atas diilhami oleh pemikiraan Sutan Takdir Alisjahbana (STA) yang menyatakan bahwa ... "berani berpikir dan berusaha menuju penyempurnaan bahasa Indonesia". (Alisjahbana, 1988: 7). Ungkapan STA telah menggugah dan membangunkan kita untuk ingat dan bersikap positif terhadap bahasa Indonesia baik secara langsung maupun tidak langsung. Pandangan, pemikiran, dan konsep STA telah menggugah bangsa Indonesia agar senantiasa bersikap positif terhadap bahasa Indonesia sebagai bahasa modern. Selain itu, bahasa Indonesia sanggup menjadi bahasa dalam era global. Menjadi bahasa dalam era global misalnya bahasa Indonesia sudah menjadi bahasa Masyarakat Ekonomi Asia Tenggara. Dalam tingkat Asia, terbukti bahasa Indonesia misalnya dalam dunia seni musik "dangdut" sudah dapat menyatukan bangsa-bangsa Asia Tenggara, yaitu Singapura, Brunai Darussalam, Malaysia, Tahiland, dan Timur Leste. Hal itu telah menunjukkan bahwa bahasa Indonesia melalui seni musik khusunya "dangdut" telah dapat menyatukan bangsa-bangsa Asia Tenggara. Dengan adannya kontes "dangdut" itu, sekurang-kurangnya peserta "dangdut Akademi" akan dituntut untuk menghapalkan lagu dan sekaligus melapalkan bahasa Indonesia secara baik dan benar.

Pemikiran, konsep, dan ancangan ke depan bahasa Indonesia oleh STA dan berdasarkan contoh gejala pemakaian dalam dunia musik tersebut di atas, kita perlu dan wajib menyikapi bahasa Indonesia dengan cara merevitalisasi bahasa Indonesia agar bahasa Indonesia tetap tumbuh dan berkembang sesuai dengan tanntangan global. Oleh karena itu, dengan merevitalisaasi pandangan STA ini sekurang-kurangnya akan mendapat pijakan yang terarah dan terencana sesuai dengan garis-garis besar haluan kebahasaan. Dengan adanya garis-garis besar haluan kebahasaan tersebut, sikap positif kita terhadap bahasa Indonesia sebagai bahasa nasional dan bahasa negara akan tercapai sesuai dengan ancangan yaitu sebagai bahasa persatuan. Untuk menyempurnakan bahasa Indonesia menjadi bahasa modern dan sekaligus menjadi bahasa dalam era global yang mendunia, kita hendaknya sanggup memberi dorongan dan sikap positif kita untuk berani berpikir dan berusaha menuju penyempurnaan bahasa Indonesia di era global ini. 


\section{Rumusan Masalah}

Berdasarkan latar belakang masalah, rumusan masalah peneliian iadalah sebagai berikut.

1. Bagaimana pandangan dan konsep STA tentang hakikat bahasa Indonesia Pujangga Baru mementingkan kesusaateraan dan bahasa Indonesia, bahasa Indonesia sebagai bahasa persatuan, pelajaran bahasa Indonesia, Pujangga Baru mementingkan kesusaateraan dan bahasa Indonesia, bahasa Indonesia dengan Sekolah Tinggi Kesusateraan., penerjemahan.

2. Bagimana bahasa Indonesia menjadi bahasa modern dan pedoman penyusunan Tata Bahasa Baru Bahasa Indonesia.

3. Bagaimana penerjemahan bahasa-asing khususnya bahasa Inggris-Indonesia.

\section{Tujuan Penulisan}

Adapun tujuan penulisan artikel adalah sebagai berikut.

1. Untuk mendeskripsikan 1. hakikat bahasa Indonesia bahasa Indonesia sebagai bahasa persatuan, 2. pelajaran bahasa Indonesia, 3. Pujangga Baru mementingkan kesusasteraan dan bahasa Indonesia, 4. bahasa Indonesia dengan Sekolah Tinggi Kesusateraan, 5. penerjemahan, 6. pedoman penyusunan Tata Bahasa Baru Bahasa Indonesia, dan 7. rancangan pelajaran bahasa Indonesia di perguruan tinggi.

2. Untuk mendeskripsikan dan mengetahui bahasa Indonesia menjadi bahasa modern. pedoman penyusunan Tata Bahasa Baru Bahasa Indonesia dan penerjemahan.

\section{Tinjauan Pustaka \\ Hakikat Bahasa}

Bahasa merupakan alat komunikasi baik secara lisan maupun tertulis. Selain itu, bahasa merupakan alat perhubungan antarwarga masyarkat yang satu dengan warga masyarakat yang lain. Sehubungan dengan itu, Martinet (1987: 32) menyatakan bahwa bahasa adalah sebuah alat komunikasi untuk menganalisis pengalaman manusia, secara berbeda di dalam setiap masyarakat, dalam satuan-satuan yang mengandung isi semantik dan pengungkapan bunyiuntuk mengadakan komunikasi dengan mempergunakan cara-cara tertentu yang telah disepakati bersama. Dengan kata lain, bahwa bahasa merupakn alat komunikasi yang telah disepakai bersama oleh masyarakat tertentu untuk berinteraksi dan beradaptasi. Di dalam berinteraksi antarsesama juga menggunakakan bahasa. Baik interaaksi itu secara langsung maupun tidak langsung.

Sementara itu, hakikat bahasa juga dinyatakan oleh Samsuri (1983: 3-5) memakai salah satu bahasa merupakan salah satu keinginan manusia untuk mengadakan hubungan dengan manusia yang lain. Pernyataan Samsuri itu telah membuktikan bahwa manusia dalam kehidupan sehari-hari perlu berinteraksi dengan sesama anggota masyarakat baik seara langsung maupun tidak langsung. Kenyataan itu telah membuktikan bahwa bahasa wajar dimiliki dan dipakai sebagai alat komunikasi oleh setiap manusia. Oleh karena itu, bahasa tidak perlu mendapat perhatian yang selayaknya sesuai dengan fungsinya di dalam masyarakat. Dengan kata lain, pendapat Samsuri dapat disimpulkan bahwa bahasa merupakan alat komunikasi yang paling vital bagi kehidupan manusia.

Pernyataan Samsuri itu menunjukkan bahwa kebudayaan kita terima dari nenek moyang melalui bahasa. Hal itu menunjukkan bahwa bahasa merupakan alat komunikasi yang paling vital dalam berbudaya. Bahasa tidak akan terpisahkan dari nilai-nilai budaya manusia dan selalu 
dapat seiring dengan aktivitas sehari-hari. Keseluruhan kegiatan manusia yang ada dalam masyarakat dapat terangkum dalam kebudayaan. Bahasa tidak saja merupakan dasar kebudayaan, tetapi juga merupakan bagian dari kebudayaan. Selain itu, bahasa merupakan kunci yang paling menghasilkan untuk membuka ciri-ciri suatu kelompok masyarakat bahasa. Kita tidak akan dapat mengetahui budaya masyarakat tertentu tanpa mengetahui dan memahami bahasa kelompok masyarakat tertentu.

Dalam hal yang sama hakikat bahasa telah dinyatakan oleh Keraf ( 1993: 1) bahasa adalah alat komunikasi antara anggota masyarakat berupa simbul bunyi yang dihasilkan oleh alat ucap manusia. Walaupun ada alat komunikasi yang lain misalnya dengan cara yang telah disepakai bersama melaui lukisan-lukisan, asap api, atau bunyi gendang. Dengan cara itu memang kurang efektif karena setiap manusia yang mempunyai adat berbeda, akan berbeda pula dalam memaknakan setiap simbol tersbut. Oleh karena itu, kecenderungan mayarakat akan menggunakan bahasa karena dengan menggunakan bahasa alat komunikasi antaranggota masyarakat akan lebih efektif jika dibandingkan dengan cara lain di luar bahasa. Hal itu juga dinyakan oleh Muhajir yang mengacu pada konsep Saussure ( 2014: 28 -29) Bahwa bahasa adalah suatu sistem tanda yang terdiri atas dua sisi yang saling melengkapi yaitu isi dan bentuk yang pertama berkaitan dengan yang ditandai (signified), dan yang kedua penanda (signifier). Oleh karena itu, dapat dikatakan bahwa hakikat bahasa pada umumnya adalah alat komunikasi antara anggota maasyarakat yang satu dengan anggota masyarakat yang lain dengan bahasa sebagai media komuniaksinya.

\section{Kedudukan dan Fungsi Bahasa Indonesia Hakikat Bahasa Indonesia}

Berbicara tentang bahasa Indonesia jika dilihat bdari sejarahnya lihat Sunaryo (2000: 1 yang telah mengutip pernyataan (Mees, 1969; Alisjahbana, 1983; Keraf, 1982; Ahmad, 1950), Bahada Indonesia berasal dari bahasa Melayu. Bahasa Melayu jika dilihat dari perkembagannya merupakan bahasa pergaulan (lingua franca) digunakan dalam berkomunikasi antarsuku di nusantara. Bahasa Indonesia berasal dari bahasa Melayu itu pada tanggal 28 Oktober 1928 telah diikrarkan sebagai "bahasa persatuan Indonesia" yang secara resmi disebut sebagai bahasa Indonesia. Bahasa Indonesia di dalam pertumbuhan dan perkembagannya selalu mengalami perubahan dan masalah baik yang menyangkaut masalah kosakata dan istilah. Oleh karaena itu, masalah-maslah bahasa Indonesia itu perlu penanganan yang khusus agar bahasa Indonesia menjadi bahasa yang dinamis.

Salah satu masalah kebahasaan yang perlu dirancang dan penggarapannya adalah masalah fungsi dan kedudukan bahasa Indonesia. Hal itu merupakan masalah yang kita anggap penting karena adanya kebijakan bahasa nasional harus mencakup adanya fungsi dan kedudukan bahasa Indonesia. Berkaitan dengan kebijakan itu, bahwa bahasa Indonesia perlu adanya garisgaris besar haluan kebahasaan. Sehubungan dengan itu, Halim (1981: 21) menyatakan bahwa kedudukan bahasa Indonesia adalah status relatif bahasa sebagai sistem lambang nilai budaya, yang dirumuskan atas nilai budaya dan nilai-nilai sosial yang dihubungkan dengan bahasa yang bersangkutan. Berkaitan dengan fungsi bahasa, dalam hubungan ini adalah adanya nilai pemakaian bahasa yang dirumuskan sebagai tugas pemakaian bahasa. Mengapa kedudukan dan fungsi bahasa Indonesa penting diancangkan karena dengan adanya garis-garis besar haluan kebahasaan, kita dapat membedakan antara fungsi dan kedudukan bahasa Indonesia dan fungsi dan kedudukan bahasa-bahasa daerah yang ada di Indonesia. Dengan demikian, ketaksaan antara 
bahasa Indonesia dan bahasa-bahasa daerah yang ada di wilayah Indonesia dapat diatasi. Selain itu, ketaksaan itu akan menghambat laju perkembangan dan pembakuan bahasa Indoneisa.

Perkembangan dan pembakuan bahasa Indonesia akan tercapai, jika ancangan garis-garis besar haluan kebahasaan disikapi dengan positif. Begitu pula dengan bahasa daerah. Bahasa Indonseia sebagai bahasa modern yang dinamis, hendaknya bersifat terbuka untuk menerima unsur-unsur bahasa lain yang diperlukan. Jika memerlukan bahasa-bahasa lain, bahasa kita hendaknya menyerasikan dengan sistem bahasa Indonesia dengan mempertahankan identitasnya.

\section{Bahasa Indonesia sebagai Bahasa Nasional}

Bahasa Indonesia sebagai bahasa nasional kita perlu bertolak gari gagasan Halim (1981:

15) yang menyatakan bahwa pengelolaan seluruh masalah bahasa Indonesia memerlukan adanya satu kebijakan nasional yang dirumuskan sedemikian rupa sehingga pengelolaan masalah bahasa itu benar-benar berencana, terarah, dan teliti. Lebih lanjut dipaparkan pula adanya perencanaan, pengarahan, dan ketentuan-ketentuan yang dapat dipakai sebagai dasar bagi pengolahan keseluruhan masalah bahasa itu yang identik dengan politik bahasa nasional.

Dengan kata lain, kebijakan bahasa nasional memerlukan perencaaan yang matang dan beristem sesuai dengan garis-garis haluan kebahasaaan yang diancangkan.

Sikap positif terhadap bahasa Indonesia sebagai bahasa nasional itu tercermin dari pandangan Halim (1981: 16) yang menyatakan bahwa salah satu fungsi politik bahasa nasional adalah memberikan dasar dan pengarahan, perencanaan, dan pengembangan bahasa nasonal yang mencakup pertanyaaan mendasar yang berhubungan dengan hal berikut.

1) Fungsi dan kedudukan dibandingkan dengan bahasa-bahasa lain;

2) Penentuan ciri-ciri bahsa Indonesia baku;

3) Tata cara pembakuan dan pengembangan bahasa nasional;

4) Pengembangan bahasa nasional pada semua jenis dan tingkat lembaga pendidikan, mulai dari tingkat taman kanak-kanak sampai dengan tingkat peguruan tinggi;

Jadi, bahasa Indonesia sebagai bahasa nasional hendaknya disikapi secara positif yaitu 1) pihak yang terkait dalam hal ini Badan Bahasa, 2) Lembaga kebahasaan, 3) pemerhati bahasa, 4) khalayak yang membidangi masalah kebahasaan, dan 5) pemakai bahasa Indonesia untuk memudahkan komunikasi antaranggota masyarakat di Indonesia. Dengan demikian, ancangan positif bahasa Indonesia sebagai bahasa nasional baik yang menyangkut tata cara pembakuan maupun pengembangan bahasa nasional dari tingkat pendidikan taman kanak-kanak hingga pertguruan tinggi akan tercapai.

\section{Bahasa Indonesia sebagai Bahasa Negara}

Bahasa Indonesia sebagai bahasa Negara, kita mengacu pada Undang-Undang Dasar 1945 Bab XV, Pasal 36 di dalam kedudukannya sebagai bahasa negara mengacu pada pandangan Halim ( 1980) dan Arifin dan Tasai (2015) bahwa fungsi bahasa Indonesia sebagai bahasa negara adalah sebagai berikut.

1. Bahasa resmi kenegaraan,

2. Bahasa pengantar di dalam dunia pendidikan,

3. Alat perhubungan pada tingkat nasional untuk kepentingan perencanaan dan pelaksanaan pembangunan, dan

4. Alat pengembangan kebudayaan, ilmu pengetahuan, dan teknologi.

Di samping itu, sebagai 
5. Bahasa media massa,

6. Bahasa sastra Indonesia, dan

7. Sebagai bahasa yang memperkaya khasanah bahasa daerah.

Konsep tersebut telah dinyatakan pula oleh Moeliono ( 1985: 38 -64dalam Garis Haluan dalam Alokasi Fungsioal Bahasa yakni adanya ancangan berikut.

1) Fungsi sosiolinguistik bahasa;

2) Bahasa Negara, Bahasa Kebangsaaan, dan Bahasa Resmi;

3) Bahasa Perhubungan luas;

4) Bahasa untuk Tujuan Khusus;

5) Bahasa di Dalam Dunia Pendidikan;

6) Bahasa Kebudayaan.

Pandanagan Moeliono itu telah memberikan pandangan dan ancangan kebahasaan untuk menyikapi secara positif tentang cakupan sosiolingusitik bahasa, fungsi bahasa Indonesia sebagai bahasa negara, bahasa kebangsaan, dan bahasa resmi negara. Selain itu, bahasa Infonesia diancangkan sebagai alat perhubungan luas, bahasa untuk tujuan khusus. Yang tidak kalah penitngnya adalah ancangan bahasa di dalam dunia pendidikan dan bahasa kebudayaan.

Rincian sikap bahasa Moeliono itu mengarahkan kepada kita untuk menyikapi secara positif terhadap bahasa Indonesia sebagai bahasa negara. Tanpa sikap positif terhadap bahasa Indonesia oleh kalangan pemakai bahasa baik secara langsung maupun tidak langsung, tujuan bahasa Indonesia sebagai bahasa negara tidak akan tercapai.

\section{METODE PENELITIAN}

\section{Metode dan Prosedur Penelitian}

Metode dan prosedur penelitian ini mengacu pandangan Wiersma dan Stephen G. Jurs (2005: 201 - 207) menyatakan bahwa pendekatan kualitatif dengan desain seperti berikut. 1) penentuan sumber data dan data 2) rumusan masalah, 3) pengumpulan data, dan 4) penganalisisan data. Pendekatan kualitatif dianggap relevan untuk penelitian ini karena tujuan, proses, dan datanya verbal, termasuk acuan teori fungsi bahasa dan kedudukan bahasa Indonesia

Penelitian ini menggunakan metode analisis isi kualitatif menurut Bogdan dan Biklen (1990: 189) yang menghendaki kategori-kategori sebagai satuan-satuan analisis, maka berbagai kategori dibuat berdasarkan acuan teori bentuk dan tujuan maupun kategori makna.

\section{Data dan Sumber Data}

Data penelitian ini adalah sebagai berikut. 1) Bahasa Indonesia sebagai Bahasa Persatuan. 2) Pelajaran Bahasa Indonesia. 3) Pujangga Baru Mementingkan Kesusaateraan dan Bahasa Indonesia. 4) Hakikat Bahasa Indonesia. 5) Bahasa Indonesia dengan Sekolah Tinggi Kesusateraan. 6) Penerjemahan. 7) Pedoman Penyusunan Tata Bahasa Baru Bahasa Indonesia. 8) Rancangan Pelajaran Bahasa Indonesia di Perguruan Tinggi. Tidak semua artikel yang ada dalam buku tersebut diteliti. Akan tetapi, penulis memmilih artikel secara bertujuan sesuai dengan kebutuhan penelitian.

Adapun sumber data penelitian ini adalah Buku Dari Perjuangan dan Pertumbuhan Bahasa Indonesia oleh Sutan Takdir Alisjahbana yang diterbitkan di Jakata oleh penerbit Dian Rakyat, terbit pada tahun 1988. 


\section{Prosedur Analisis Data}

Pengumpulan data penelitian ini dilakukan dengan langkah-langkah sebagai mana penelitian yang didesain oleh Wiersma ( 2005: 201-207) sebagai berikut.

1) Menentukan sumber data dan data penelitian;

2) Mengajukan pertanyaan dalam rumusan masalah;

3) Mengumpulkan data;

4) Menganalisis, mengintepretasi temuan data;

5) Menyimpulkan hasil penelitian.

\section{HASIL DAN PEMBAHASAN}

\section{Bahasa Indonesia Bahasa Persatuan}

Bahasa Indonesia bahasa persatuan (BIBP) Artinya bahasa Indonesia sebagai bahasa persatuan ini dibuktikan adanya pendapat Sutan Rakdir Alisjahbana (STA) yaitu pada kutipan berikut ini.

"Bahasa Melayu yang diangkat menjadi bahasa Indonesia seperti kami katakan, berarti kekalahan bagi bahasa Belanda. Sumpah pemuda2 kita beberapa tahun yang lalu, bahwa hanya satu bahasa, yaitu bahasa Indonesia, seolah2 dimusuhi”. (BIBP/ 1988/ 13/3)

Kutipan pendapat STA tersebut di atas membuktikan bahwa bahasa Indonesia telah diikrarkan melaui Sumpah Pemuda pada tanggal 28 Oktober 1928 itu menunjukkan bahasa persatuan adalah bahasa Inonesia. Hal itu membuktikan bahwa bangsa Indonesia tidak lagi menggunakan bahasa Belanda sebagai bahasa persatauan. Penggunaaan bahasa Indonesia sebagai bahasa persatuan itu dianggap oleh orang Belanda memusuhi bahasa Belanda.

Pernyataan di atas, jika dikaitkan dengan fungsi bahasa Indonesia sebagai bahasa nasional pada butir ketiga yaitu masih relevan sebagai Alat Penyatuan Berbagai Suku Bangsa dan Bahasanya Masing-masing ke dalam Kesatuan Bahasa Inonesia.

Bahasa Indonesia sebagai alat penyatuan berbagai suku bangsa dan bahasanya masingmasing ke dalam kesatuan kebangsaan Indonesia maksudnya adalah bahwa bahasa Indonesia tidak akan menghambat komunikasi antardaerah dan antarsuku di wilayah Negara Kesatuan Republik Indonesia. Dengan adanya bahasa Indonesia sebagai penyatu bangsa, kesalahpahaman anatarsuku dan latar belakang sosial budaya dapat diantisipasi, sehingga komunikasi antarwilayah di Indonesia tetap terjaga keutuhannya. Selain itu, arus perpindahan penduduk dari tempat yang satu ke tempat yag lain, perkawinan antarsuku yang berbeda bahasa daerah dengan komunikasi melalui bahasa Indonesia dapat terjamin.

"Bahasa Inonesia menyatukan diriya dengan membelakangi bangsa Belanda. Persatuan di kalangan bangsa Indomesia terlangsung atas pimpinan dan tuntunan atas pihak Indonesia sendiri tiada memedulikan bangsa Belanda. Padahal bangsa Belanda mengharapkan persatuan atas pimpinan mereka dengan bahasa mereka". (BIBP/ 1988/ 13/4)

Pernyataan STA tersebut di atas membuktikan bahwa dengan adanya bahasa Indonesia sebagai alat pemersatu bangsa Indonesia dianggap oleh orang Belanda telah membelakangi bangsa Belanda. Hal itu dilakukan bukan atas perintah dan tuntunan orang Belanda, melainkan atas inisiatif pihak Indonesia sendiri tanpa memedulikan bangsa Belanda. Padahal, bangsa Belanda mengaharapakn dengan bahasa Belanda-lah bangsa Indonesia dapat dipersatukan. 
Karena dengan memakai bahasa Belanda, Pemerintah Belanda ingin memecahkan persatuan bangsa Indonesia dengan bahasa mereka. Rupanya keinginan bangsa Belanda itu tidak disikapi oleh bangsa Indonesia. Dengan kata lain, bangsa Indonesia tetap positif memertahankan bahasa Indonesia sebagai bahasa perstuan.

\section{Pengajaran Bahasa}

Pengajaran Bahasa (PB) telah diancangkan pula oleh STA berikut ini.

“ Dan bolehlah kita berhari2 membalik segala macam buku pelajaran dan bacaan bahasa Indonesia yang dipakai di sekolah, tetapi usaha kita akan mencapai jejak perasaan keindahan tentang bahasa itu akan sia2 belaka”. (PB/1988/17/6)

STA telah membuktikan ketegasannya bahwa bahasa Indonesia hendaknya dipakai di sekolah-sekolah sebagai bahan pelajaran dan bacaan. Walaupun kenyataannya pada waktu itu belum mendapat tanggapan yang serius dari Pemeintah dan belum mendapat hasil yang memuaskan. Akan tetapi, perjuangan STA itu hingga sekarang merupakn pijakan bagi bangsa Indonesia, bahwa bahasa Indonesia telah dipakai sebagai bahasa pengantar dalam dunia pendidikan.

Pengajaran bahasa yang dimaksud adalah bahasa pengantar dalam dunia pendidikan. Bahsa Indonesia sebgai bahasa pengantar dalam dunia pendidikan sejalan dengan fungsi bahasa Indonesia sebagai bahasa Negara pada butir kedua yaitu Bahasa Pengantar di dalam Duni Pendidikan.

Bahasa pengantar di dalam dunia pendidikan, bahasa Indonesia dipakai dalam kegiatan pendidikan dari tingkat sekolah dasar sampai dengan tingkat perguruan tinggi. Selain itu, bahasa Indonesia juga secara resmi dipakai dalam konteks pendidikan luar sekolah, kursus-kursus dan kegiatan sejenis menggunakan bahasa Indonesia sebagai bahasa pengantar. Akan tetapi, di samping pengunaan bahasa Indonesia sebagai pengantar dalam dunia pendidikan juga adanya muatan lokal yaitu mata sajian bahasa daerah untuk daerah-daerah. Misalnya daerah Jawa Tengah, Jawa Barat, Bali, Banjar, dan Bugis wajib menggunakan bahasa daerah masing-masing sebagai muatan lokal.

\section{Pujangga Baru Mementingkan Kesusaateraan dan Bahasa Indonesia}

Pujangga Baru mementingkan kesusasteraan dan bahasa Indonesia telah dinyatakan STA dalam Membatasi Tugas Guru dan Tugas Pujangga (MTGP) berikut ini.

" Hal ini bukan berarti, bahwa kita hendak mewatasi kebebasan penyair menulis seperti terasa kepadanya. Hal ini hanya berarti penyair bekerja di lapangannya sendiri, mencurahkan isi perasaannya. Sedangkan guru bekerja pula di lapanggannya”. (MTGTP/ 1988/188/2)

STA telah memberikan pandangan bahwa seorang penyair tidak harus dibatasi dalam berkarya. Penyair mempuyai lapangan sendiri dan bekerja di lapangan sendiri, mencurahkan isi perasaannya melaui karya-karyanya. Sementara itu, guru juga mempunyai lapangan sendiri yakni memberikan pelajaran sastra dan bahasa melalui gaya dan coraknya masing-masing. Dengan kata lain, penyair dan guru mempunyai tugas yang sama. Penyair berkarya melalui bahasa sebagai medianya, sedangkan guru mengajar, bahasa sebagai media komunikasi baik secara langsung maupun tidak langsung.

\section{Hakikat Bahasa Indonesia}

Hakikat Bahasa Indonesia (HBI) menurut STA adalah sebagai berikut. 
"Bahasa Indonesia ialah bahasa perhubugan yang berabad2 tumbuh per-lahan2 di kalangan penduduk Asia Selatan dan yang setelah bangkitnya pergerakan kebangunan rakyat Indonesia pada permulaan abad kedua puluh dengan insaf diangkat dan dijunjung sebagai bahasa persatuan “. (HBI/1988/7/4)

STA telah memberikan pandangan tentang hakikat bahasa Indonesia yakni bahwa bahasa Indonesia merupakan alat komunikasi sejak berabad-abad. Bangkitnya rakyat Indonesia mulai abad kedua puluh bahwa bahasa Indonesia diangkat dan dijunjung sebagai bahasa persatuan Indonesia. Bahwa bahasa Indonesia merupakan terusan dari bahasa Melalyu. Setapak demi setapak bahasa Indonesia mempunyai kedudukan yang laik sebagai bahasa perhubungan pada tingkat nasional. Bahasa Indonesia dipakai alat pergaulan penduduk nusantara yang saat ini mencapai 260 jutaan. Bahasa Indonesia, sebagai bahasa perhubungan dan bahasa persatuan mengalami perkembangan yang dinamis.

Bahasa Indonesia sebagai alat perhubungan antarwarga, antardaerah, dan antarbudaya bahwa bahasa Indonesia dapat menyatukan hubungan antarwarga dan antardaerah melaui bahasa Indonesia sebagai medianya sebagai pengungkap rasa antarsesama di wilayah Negara Kesatuan Republik Indonesia. Hal itu termasuk hubungan antarbudaya bahwa dengan media bahasa Indonesia, informasi tentang kebudayaan daerah yang ada di wilayah dapat diinformasikan melalui bahasa Indonesia. Dengan demikian, kita tambah percaya diri dan bangga terhadap bahasa Indonesia.

\section{Bahasa Indonesia dengan Sekolah Tinggi Kesusateraan}

STA telah merencanakan Bahasa Indonesia dengan Sekolah Tinggi Kesusateraan (BIDSTK) dalam kutipan berikut ini.

“ Tetapi meski bagaimana sekalipun besarnya keinginan dari pihak bangsa Indonesia untuk memajukan dan menyempurnakan bahasa persatuannya itu, hasil usahanya tidaklah seberapa, olah karena kekurangan uang dan kekurangan tenaga yang terdidik, cakap dan mempunyai minat dan waktu. ( BIDSTK/1988/76/5)

STA telah mempunyai pandangan, bahwa bahasa Indonesia dalam Kongres Bahasa Indonesia pada tahun 1938 di Solo oleh beberapa golongan dicap sebagai demonstrasi politik. Dengan demikian, usaha untuk mengadakan kegiatan semacam kongres itu mengalami hambatan adanya kekurangan dana, termasuk kekurangan tenaga terdidik yang mempunyai minat dan waktu untuk memikirkan, memprakarsai, dan meyempurnakan bahasa Indonesia.

Penyempurnaan bahasa Indonesia itu perlu adanya perjuangan yang keras karena dengan usaha yang keras dan keinsafan, bahasa Indonesia akan menjadi bahasa yang penting dalam masyarakat yang maju yang mau menghargai nilai-nilai budaya yang sedang tumbuh dan berkembang di negeri ini. Bahasa tidak akan tumbuh tanpa budaya, sebaliknya budaya tidak akan tumbuh dan berkembang tanpa bahasa.

Pandangan STA itu menunjukkan bahwa untuk mengantisipasi pertumbuhan bahasa Indonesia perlu dan wajib adanya Sekolah Tinggi Kesusteraan. Hanya dengan jalan demikian, sekolah tinggi itu akan menjadi tenaga pembangunan yang positif dalam masyarakat. Dengan kata lain, adanya Sekolah Tinggi Kesusateraan (sekarang Fakultas Ilmu Budaya/Fakukltas Sastra/Fakultas Bahasa dan Seni) akan menghasilkan tenaga yang terdidik dan cakap untuk melalakukan pekerjaan yang kreatif, inovatif, penciptaan ikhwal bahasa dan sastra untuk menyempurnakan dan mengembangakan bahasa dan sastra Indonesia. 


\section{Penerjemahan}

Berbicara tentang penerjrmahan, STA telah memberikan beberapa pandangan tentang petunjuk menerjemahkan (PM) seperti berikut. Pertama, "Hendak kami ingatkan kepada para penerjemah, janganlah menerjemahkan sesuatu, sebelum mengerti karangan, maupun mengenai kalimat atau kata. Kalau kita terus menerjemahkan juga sesuatu yang kita belum mengerti, samalah kita me-nerka2 saja. Sebab itu, dalam menerjemahkan, janganlah segan2 bertanya kepada orang yang tahu tetang isi karangan itu, bertanya tentang makna kalimat dan kata, membuka kamus atau kitab2 yang lain untuk mendapat keterangan”. (PM/1988/100/4)

Maksunya adalah bahwa seorang penerjremah hendaknya memahami isi karangan yang akan diterjemhakan. Seorang penerjemah juga dituntut untuk memahmi makna kalimat dan kata yang akan diterjemahkan. Dalam menerjemhakan tidak boleh hanya menerka-nerka tentang kata, kalimat, dan isi karangan. Oleh karena itu, yang diharapkan adalah bahwa seorang penerjermah hendaknya mau bertanya tentang kalimat dan kata kepada orang yang lebih memahami ikhwal penerjemmahan. Selain itu, seoarng penerjemah diharapkan mau membuka kamus, atau glosarium untuk mendapatkan keterangan tentang apa makna dan arti dari kalimat, frasa, dan kata.

Kedua, "Hendaklah pahamkan dahulu, apa yang dimaksud dengan terjemahan itu. Terjemahan yang maksudnya memberi penerangan kepada orang banyak, berbeda sifatnya dari terjemahan kitab ilmu atau undang2, yang tiap2 katanya harus dibuat menjadi tempat berpegang”. (MP/1988/100/5)

Penerjemah selain mengerti dan memahami ikhawal penerjemhan petunjuk pertama, juga harus memperhatikan petunjuk kedua. Seorang penerjemah hendaknya memahami dahulu apa yang dimaksud dengan penerjemahan itu. Artinya seorang penerjemah mengerti dan memahami ikhwal penerjemhan secara total. Tugas seorang penerjemah adalah memberikan informasi atau memberi penerangan kepada khalayak umum agar khalayak dapat mengerti dan memahmi apa diterjemhakan. Selain itu, Seorang penerjemah hendaknya dapat membedakan buku-buku ilmiah, buku nonilmiah, dan buku undang-undang.

Konsep dan pandangan STA memberikan gambaran dan garis-garis besar penerjemhan. Diharapkan agar penerjemah dapat mengembangkan profesinya untuk menerjemahkan secara besar-besaran buku-buku berbahasa asing. Buku-buku yang dimaksud misalnya buku berbahasa Inggris, Jerman, Belanda, Jepang, Korea, dan Mandarin. Dengan cara demikian itu, bangsa Indonesia diharapkan siap menerima kemajuan ilmu pengetahuan dan teknologi secara global.

\section{Pedoman Penyusunan Tata Bahasa Baru Bahasa Indonesia}

STA telah mencangkan adanya Soal dan Pedoman Menyusun Tatabahasa Indonesia Baru (SPMTTIB). Adapun ancangan STA berkaitan dengan Tatabahasa Indonesia Baru adalah sebagai berikut.

" Tatabahasa untuk zaman ini mesti lebih daripada itu, ia mesti mengadakan ketetapan dalam keadaan yang belum tetap, ia mesti memilih diantara ber-bagai2 aturan yang ber-beda2 itu, yang mana yang se-baik2nya menurut kehendak zaman dan kebudayaan Indonesia yang sedang tumbuh. Dengan pendek ia mesti normatif. (SPMTTIB/1988/108/2)

Kutipan pernyataan STA tersebut menghendaki adanya kerja keras para penyusun untuk menciptakan buku Tata Bahasa Indonesia Baru. Adanya kaidah-kaidah yang diciptakan itu, diharapkan Tatabahasa Indonesia Baru yang normatif dengan mempertimbangkan dan menetapkan sifat-sifat bahasa Indonesia, pengaruh bahasa daerah, dan pengaruh bahasa-bahasa dan pikiran modern. 
Sifat normatif menuntut agar kita daapat membedakan aturan yang perlu dan maenguntungkan bahasa Indonesia. Dengan menyikapi aturan itu, berarti kita harus mencocokkan diri kepada cara berpikir yang modern, dengan kaidah-kaidah yanag berlaku dan tidak bersangkut paut dengan syarat-syarat cara-cara berpikir. (SPMTTIB/1988/109/4)

\section{Rancangan Pelajaran Bahasa Indonesia di Perguruan Ttinggi}

Ancangan STA Mengubah Rancangan Pelajaran Bahasa Indonesia di Pperguruan Ttinggi (RPBIPT) adalah perlu dan wajib. Hal itu dilakukan untuk mengantisipasi perkembangan bahasa Indonesia menujun era modern. Untuk itu, dapat kita lihat pada kutipan pandangan STA berikut ini.

"Untuk sesungguhnya memajukan bahasa Indonesia sekarang tidak boleh tidak kita pertama sekali mesti memperbaiki keadaan pengajaran bahasa Indonesia pada perguruan tinggi itulah kita harapkan pimpinan yang sadar dan teratur dalam memnghadapi soal2 perkembangan bahasa Indonesia sebagai bahasa modern yang sekarang ini amat terbengkelai". (RPBIPT/1988/232/2)

STA telah mengancangkan rencana pembelajaran Bahasa Indonesia, betapa pentingnya pengajaran Bahasa Indonesia di Perguruan Tinggi. Penting dilakukan karena bahasa Indonesia tidak akan bisa berkembang secara dinamis tanpa adanya penanganan yang khusus oleh para pimpinan lembaga terkait dan pakar-pakar bahasa di Perguruan Tinggi. Oleh karena itu, perlu perubahan rencana pembelajaran bahasa Inddonesia yang relevan untuk mengimbangi dan menyikapi keadaan masyarakat modern.

Berdasarkan paparan di atas, STA menggarisbawahi adanya rancangan pembelajaran bahasa Indonesia di Perguruan Tinggi baik di negeri maupun swasta. Untuk itu, "yang paling memuaskan ialah memberikan kebebasan kepada mahasiswa yang hendak mempelajari bahasa Inonesia, untuk memilih pelajaran ke arah dunia modern dengan bahasa2 dan kebudayaan modern, dengan pelajaran ke arah kelasik dengan bahasa Sangsekerta dan bahasa Arab dan kebudayaan sekitar kedua bahasa itu". (RPBIPT/1988/234-235/5)

Pandangan STA tentang perubahan kurikulum adalah penting. Hal itu dilakukan karena adanya kurikulum yang memadai di Perguruan Tinggi, sasaran bahasa Indonesia menuju era modern dan era global akan tercapai. Namun, perlu adanya peran serta lembaga Pemerintah yang terkait dan Lembaga Swasta, para pakar, dosen, guru, dan pemerhati masalah kebahasaan dan kesastraan. Jika komponen terebut sinergi dan dapat bekerja sama, bahasa Indonesia siap menjadi bahasa yang mendunia dalam era global.

\section{PENUTUP \\ Simpulan}

Berdasarkan hasil pembahasan, Revitalisasi Sejarah dan Pertumbuhan Bahasa Indonesia ancangan Sutan Takdir Alisjahbana dapat disimpulkan sebagai berikut. STA telah mencanangkan garis-garis besar haluan kebahasaan, yakni sejarah dan pertumbuhan bahasa Indonesia menuju bahasa modern yaitu dengan cara merencankan dan menyikapi secara taat asas. Selain itu, atas dasar Sumpah Pemuda pada tanggal 28 Oktober 1928, butir ketiga yakni Kami putera dan puteri Indonesia, menjunjung bahasa persatuan, bahasa Indonesia dan hasil Kongres Bahasa Indonesia I di Solo, Tonggak Perkembaangan Bahasa Indonesia, maka diancangkan tentang hal berikut. 1) Bahasa Indonesia sebagai Bahasa Persatuan. 2) Pelajaran Bahasa Indonesia 3) Pujangga Baru Mementingkan Kesusaateraan dan Bahasa Indonesia. 4) Hakikat Bahasa Indonesia. 5) Bahasa Indonesia dengan Sekolah Tinggi 
Kesusateraan. 6) Penerjemahan. 7) Pedoman Penyusunan Tata Bahasa Baru Bahasa Indonesia. 8) Rancangan Pelajaran Bahasa Indonesia di Perguruan Tinggi. Jika hal itu dilakukan dengan seksama, ancangan bahasa Indonesia sebagai bahasa nasional dan bahasa negara menuju bahasa modern di era global akan terwujud.

\section{Saran}

Revitaslisai tanggung jawab Sutan Takdir Alisjahbana tentang sejarah dan perkembangan bahasa Indonesia memang belum banyak dilakukan oleh para peneliti atau mahasiswa. Oleh karena itu, masih banyak celah untuk menggali dan meneliti pernyataan STA tentang sejarah dan pertumbuhan bahasa Indonsia. Sehubungan dengan itu, masalah kebahasaan karya STA yang belum tergali dan diteliti, misalnya Menuju Kongres Bahasa Indonesia, Arti dan Guna Tatabahasa, Peribahasa, Bahasa Indonesia dan Bahasa Daerah, Kemajuan Bahasa Indonesia, Sejarah Kesusastraan Indonesia, dan Bahasa Indonesia untuk Penutur Asing. 


\section{DAFTAR PUSTAKA}

Ahmad, Sabaruddin.1950. Seluk-beluk Bahasa Indonesia. Medan: "Saiful”.

Alisjahbana, Sutan Takdir. 1983. Tata Bahasa Baru Bahasa Indonesia. Jilid I. Jakarta: Dian Rakyat.

1988. Dari Perjuangan dan Pertumbuhan Bahasa Indonesia. Jakarta: Dian Rakyat.

Bogdan, Robert C. dan Sari Knoop Biklen. 1990. Riset Kualitatif untuk Pendidikan: Pengantar dan Metode. Terjemahan. Jakarta: Pusat Antar-Universitas.

Data Pengembangan dan Pelindungan, Badan Pengembangan dan Pembinaan Bahasa sampai dengan 18 Oktober 2016.

Halim, Amran.Editor. 1981. Politik Bahasa Nasional. Jakarta: PN Balai Pustaka.

Kasno A.S. dan M. Noor Anzali. 2015. "Perencanaan Bahasa Indonesia dalam Era Globalisasi". Dalam Pujangga: Jurnal Bahasa dan Sastra. Volume 1. Nomor 2. Desember.

Keraf, Gorys. 1982. Tata Bahasa Indonesia. Ende-Flores: Nusa Indah.

----.-. 1993. Komposisi” Sebuah Pengantar Kemahiran Bahasa. Cetakan ke-9. Ende: Nusa Indah.

Martinet, Andre. 1987. Ilmu Bahasa: Pengantar. Jakarta: Kanisius.

Mees, C.A. 1969. Tata Bahasa dan Kalimat. Kuala Lumpur: University of Malaya Press.

Muhadjir. 2014. Semantik dan Pragmatik. Kota Tangerang: Pustaka Mandiri.

Samsuri, 1983. Analisis Bahasa: Memahami Bahasa Secara Ilmiah. Jakarta: Erlangga.

Sunaryo, Adi. 2000. Pilar-Pilar Bahasa Indonesia. Jakarta: Pusat Bahasa, Departemen Pendidikan Nasional.

Wiersma, William dan Stephen G. Jurs. 2005. Research Methods in Education: An Introducion, Eight Edition. Boston: Allyn and Bacon. 